tác động về việc phân biệt giữa các khối u lành tính và ác tính. ${ }^{4}$ Mức chênh lệch giữa giá trị AUC rất thấp giữa hai mô hình $A D N E X$ có $C A 125$ và ADNEX không có CA 125. Trong nghiên cứu của chúng tôi, sự khác biệt này không có ý nghĩa với $Z=1,007$ và $p=0,31$, tương tự như nghiên cứu của tác giả Sayasneh.

Các nghiên cứu về giá trị của mô hình IOTA ADNEX luôn cố gắng để tìm ra được ngưỡng cắt tôi ưu của nguy cơ ác tính. ${ }^{5}$ Việc tìm ra ngưỡng cắt tối ưu hợp lý giúp cho các bác sĩ xác định các khối u lành tính với đô đặc hiệu cao hơn, giúp tránh được các cuộc phẫu thuật không cân thiết các khối u lành tính, vì mục tiêu của điều trị bao gồm cả tăng chất lượng cuộc sống bệnh nhân bao gồm cả mong muốn sinh con. Tuy nhiên, nhóm IOTA cũng không đề xuất một cách chung thuật toán áp dụng với các ngưỡng cắt cố định, vì nhóm cho rằng, mô hình sẽ được sử dụng trong hoàn cảnh nào là rất quan trọng. ${ }^{4} \mathrm{Nghiên}$ cứu của chúng tôi cho thấy ngưỡng cắt tối ưu đối với mô hình IOTA ADNEX có CA 125 là $24,5 \%$ và với mô hình IOTA ADNEX không có Ca 125 là 25,2\%. Đồng thời, tại các ngưỡng cắt tối ưu, cả hai mô hình đều cho giá trị chẩn đoán nguy cơ ác tính giống nhau ( $\mathrm{Se}=92,3 \%, \mathrm{Sp}=$ $96,8 \%, \mathrm{PPV}=96 \%, \mathrm{NPV}=93,8 \%$ và $\mathrm{Acc}=$ $94,7 \%)$. Ngưỡng này cao hơn so với ngưỡng cắt thường sử dụng $(10 \%){ }^{3}$ thấp hơn nghiên cứu của Soo Young Jeong (47,3\%). ${ }^{5}$ Tuy nhiên, nghiên cứu của chúng tôi cho thây, ở ngương cắt $15 \%$, cả hai mô hình IOTA ADNEX đều có độ chính xác không có khác biệt nhiều với nghiên cứu của Van Castle. ${ }^{6}$ Do đó, chúng tôi cho rằng, giá trị ngưỡng cắt $15 \%$ có thể được đưa ra để xem xét đánh giá nguy cơ lành tính - ác tính của u buồng trứng tại bệnh viện $K$, giúp đưa ra chiến lược điều trị thích hợp.

\section{KẾT LUÂ̂N}

Mô hình phân loại IOTA ADNEX có CA 125 và IOTA ADNEX không có CA 125 đều có giá trị cao và tương đồng trong chẩn đoán phân biệt u buồng trứng lành tính - ác tính ở bệnh viện $\mathrm{K}$. Việc áp dụng mô hình IOTA ADNEX giúp cải thiện chẩn đoán trước phẫu thuật và góp phần đưa ra chiến lược điều trị thích hợp.

\section{TÀI LIÊU THAM KHẢO}

1. Foti PV, Attinà G, Spadola $S$, et al. MR imaging of ovarian masses: classification and differential diagnosis. Insights Imaging. 2016;7(1):21-41. doi:10.1007/s13244-015-0455-4

2. Nam G, Lee SR, Jeong $K$, Kim SH, Moon H-S, Chae HD. Assessment of different NEoplasias in the adneXa model for differentiation of benign and malignant adnexal masses in Korean women. Obstet Gynecol Sci. 2021; 64(3):293-299. doi: $10.5468 /$ ogs.21012

3. Lê Ngoc Diệp, Tô Mai Xuân Hông. Giá trị dự đoán độ ác tính u buồng trứng của mố hình IOTA ADNEX tai bênh viên Từ Dũ. Y học TP Hồ Chí Minh. 2019;23 (2):207-213.

4. Sayasneh A, Ferrara $L$, De Cock B, et al. Evaluating the risk of ovarian cancer before surgery using the ADNEX model: a multicentre external validation study. $\mathrm{Br} \mathrm{J}$ Cancer. 2016;115(5):542-548. doi:10.1038/bjc.2016.227

5. Jeong SY, Park BK, Lee YY, Kim T-J. Validation of IOTA-ADNEX Model in Discriminating Characteristics of Adnexal Masses: A Comparison with Subjective Assessment. JCM. 2020;9(6):2010. doi: $10.3390 / j \mathrm{~cm} 9062010$

6. Van Calster B, Van Hoorde $K$, Valentin $L$, et al. Evaluating the risk of ovarian cancer before surgery using the ADNEX model to differentiate between benign, borderline, early and advanced stage invasive, and secondary metastatic tumours: prospective multicentre diagnostic study. BMJ. 2014; 349(oct07 3):g5920-g5920. doi:10.1136/bmj.g5920

\title{
QUẢN LÝ ĐIỀU TRI NGƯỜI BỆNH TĂNG HUYẾT ÁP TẠI PHƯờ'NG HỒNG HÀ, THÀNH PHỐ HẠ LONG, QUẢNG NINH NẰM 2021
}

\section{Nguyễn Thị Linh*, Đặng Thị Thương**, Lê Vĩnh Giang***}

\section{TÓM TẮT}

*TTYT Thành phố Ha Long

**Viện Vệ sinh dịch tễ Trung ương

**Trường Đại học Y Hà Nội

Chịu trách nhiệm chính: Nguyễn Thị Linh

Email: nguyenlinh.khth87@gmail.com

Ngày nhận bài: 9.7.2021

Ngày phản biện khoa học: 6.9.2021

Ngày duyệt bài: 13.9.2021
Muc tiêu. Mô tả thức trang quản lý điều tri người bệnh tăng huyết áp từ 25 tuổi trở lên và một số yếu tố liển quan tại phướng Hồng Hà, thành phố Hạ Long, Quảng Ninh, năm 2021. Đối tượng và phương pháp nghiênn cứu. Nghiên cứu mô tả cắt ngang thực hiện trên 250 người trưởng thành đã được chẩn đoán mắc tăng huyết áp, đang sinh sống tai phường Hồng Hà, thành phố Hạ Long, tỉnh Quảng Ninh từ tháng 1/2021 đến tháng 09/2021. Kết quả. Trong tổng số bênh nhân THA được quản lý điều trị, $88,4 \%$ BN được quản lý hiệu quả. Mô hình hồi quy đa biến cho thấy có mối liên quan giữa tình trạng quản lý điều trị THA hiệu quả 
và nhóm tuổi từ $70-79(\mathrm{aOR}=8,00)$ và <70 tuổi $(\mathrm{aOR}=6,80)$, thời gian điều trị THA $>5$ năm $(\mathrm{aOR}=$ $3,09)$, không có bệnh kèm theo $(\mathrm{aOR}=3,21)$, không hút thuốc lá $(\mathrm{aOR}=11,91)$, có hoạt động thể lực (aOR $=6,89$ ). Kết luận. Cần quan tâm quản lý điều trị trên những nhóm bệnh nhân có tình trạng quản lý điều trị hiệu quả thấp hớn.

Tư khóa. Quản lý, điều trị, tăng huyết áp.

\section{SUMMARY}

TREATMENT MANAGEMENT PATIENTS WITH HYPERTENSION IN HONG HA WARD, HA LONG CITY, QUANG NINH, IN 2021

Objective. Describe the status of management and treatment of hypertensive patients and some related factors in Hong Ha ward, Ha Long city, Quang Ninh, in 2021. Subjects and methods. A crosssectional descriptive study was produced among 250 adults diagnosed with hypertension, living in Hong $\mathrm{Ha}$ ward, Ha Long city, Quang Ninh province from January 1. 2021 to September 2021. Results. Of the total number of hypertensive patients managed, $88.4 \%$ of patients were effectively managed. The multivariable regression model showed that there was an association between the effective management of hypertension and age $70-79(\mathrm{aOR}=8.00)$ and $<70$ years old $(\mathrm{aOR}$ $=6.80)$, duration of treatment $>5$ years $(\mathrm{aOR}=$ 3.09), no comorbidities ( $\mathrm{aOR}=3.21)$, no smoking $(\mathrm{aOR}=11.91)$, physically active (aOR 6.89). Conclusion. It is necessary to pay attention to manage patients with lower effective treatment management status.

Keywords. Management, treatment, hypertension.

\section{I. ĐĂT VẤN ĐỀ}

Tăng huyết áp (THA) là một vấn đề sức khỏe đáng quan tâm và là nguyên nhân hàng đầu dẫn đến tử vong sớm trên thế giới. Theo tổ chức $Y$ tế thế giới (WHO), trên toàn thế giới ước tính có khoảng 1,28 tỳ người bị tăng huyết áp [5], dự đoán số người bị tăng huyết áp sẽ tăng lên 1,56 tỷ người vào năm 2025 [9]. Điêuu tra quốc gia (STEPS) về các yếu tố nguy cơ của bệnh không lây nhiểm (NCDs) năm 2015 cho thây tỷ lệ THA ở Viêt Nam là $18,9 \%$, tỷ lê này ở nam $(23,1 \%)$ cao hơn đáng kể so với ở nữ $(14,9 \%)$. Trong số những người được phát hiện THA, chỉ có $43,1 \%$ cho biết đã được chẩn đoán, và chỉ 13,6\% cho biết ho đang được quản lý tại cơ sở y tế [1]. Với tính chất của bệnh, người bệnh cần phải theo dõi huyết áp và dùng thuốc ha áp suốt đời, kết hợp với các biện pháp thay đổi lối sống lành mạnh, giảm thiểu các yếu tố nguy cơ gây THA. Tuy nhiên việc tuân thủ các nguyên tắc điều trị kế trên đối với người bệnh THA thường không dễ dàng. Quản lý THA cần có sự nỗ lực và phối hợp từ phía người bệnh, hệ thống y tế, gia đình cũng như cộng đồng, nhằm hướng tới mục tiêu giúp người bệnh THA cảm thây dễ dàng hớn, tuân thủ tốt hơn và từ đó kiểm soát THA trở nên có hiệu quả hơn [6]. Tại tỉnh Quảng Ninh, theo số liệu báo cáo của $C D C$ Quảng Ninh từ năm 2019 đến hết tháng $6 / 2020$ cho thấy tỷ lê THA ở người trên 40 tuổi chiếm 27,79\% [3]. Từ thực tế trên, chúng tôi tiến hành đề tài nghiên cứu này nhằm mô tả thực trạng quản lý điều trị người bệnh tăng huyết áp và một số yếu tố liên quan tại phường Hồng Hà, thành phố Hạ Long, Quảng Ninh, năm 2021.

\section{II. ĐỐI TƯỢNG VÀ PHƯƠNG PHÁP NGHIÊN CỨU 2.1. Thời gian và địa điểm nghiên cứu}

- Thời gian nghiên cứu: Từ tháng 1/2021 đến tháng 09/2021

- Địa điểm: Phường Hồng Hà thành phố Hạ Long tỉnh Quảng Ninh

2.2. Đối tượng nghiên cứu: Người trên 25 tuổi đã được chẩn đoán mắc THA, đang sinh sống tại phường Hồng Hà, thành phố Hạ Long, tỉnh Quảng Ninh.

Tiêu chuẩn lựa chọn: (1) Người có hộ khẩu thường trú tại phường Hồng Hà, thành phố Hạ Long, tỉnh Quảng Ninh, (2) Người đã được chẩn đoán là THA bởi các cơ sở y tế có thẩm quyền.

Tiêu chuẩn loại trư: (1) Không đồng ý tham gia vào nghiên cứu, (2) Người bị tâm thần, rối loạn trí nhớ, (3) Người không có hoặc đã mât khả năng nghe, nói và trả lời.

2.3. Thiết kế nghiên cứu: Mô tả cắt ngang

2.4. Cõ̃ mẫu và phương pháp chọn mẫu:

Cỡ mẫu: 250 bệnh nhân THA

Phương pháp chọn mẫu: Chọn toàn bộ người trên 25 tuổi đã được chẩn đoán mắc THA và đáp ứng tiêu chuẩn nghiên cứu.

2.5. Quy trình nghiên cứu. Dựa theo danh sách $B N$ được quản lý điều trị THA ở Trạm $Y$ tế phường, liên hệ với BN thông qua số điện thoại. Sau đó điều tra viên đến tận nhà $B N$ hoặc mời BN đến trạm y tế (tuỳ địa điểm nào $B N$ cảm thấy phù hợp), giải thích về mục đích của nghiên cứu, mời đối tượng tham gia vào nghiên cứu.

Điều tra viên thực hiện phỏng vấn theo bộ câu hỏi có sẵn bằng giấy, sau đó đo huyết áp bệnh nhân tại thời điểm phỏng vấn.

2.6. Biến số, chỉ số nghiên cứu: (1) Biến phụ thuộc: thang điểm quản lý tăng huyết áp được phân loại theo thang điểm bao gồm: đạt huyết áp mục tiêu (5 điểm) và 4 nhóm yếu tố thuộc về hệ thống quản lý, tuân thủ điều trị của người bệnh, nhận được sự hỗ trợ của người thân và nhận được sự hỗ trợ của xã hội (mỗi câu 1 điểm) với tổng điểm là 21 . Bệnh nhần được đánh giá là được quản lý hiệu quả khi tổng điểm $\geq$ 
$70 \%$ tổng số điểm/ $\geq 14$ điểm và không hiệu quả khi tổng điểm < 14 điểm; (2) Biến số độc lập: tuổi, giới tính, trình độ học vấn, bệnh kèm theo, thời gian điều trị THA, các hành vi nguy cơ.

2.7. Quản lý và phân tích số liệu: Số liệu được nhập, làm sạch bằng phần mểm Epidata 3.1 và xử lý số liệu bằng phần mềm SPSS 26. Sử dụng tần số, tỷ lệ \% cho biến định tính; sử dụng giá trị trung bình, trung vị, độ lệch chuẩn cho biến định lượng. Phân tích hồi quy logistic đơn biến và đa biến được sử dụng để xác định một số yếu tố liên quan đến tình trạng quản lý điều trị THA.

2.8. Đạo đức nghiên cứu: Nghiên cứu phải được sự thông qua hội đồng bảo vệ đề cương trường Đại học Y Hà Nội. Trước khi tham gia nghiên cứu, đối tượng được giải thích về mục đích, nội dung của nghiên cứu và tự nguyện tham gia vào nghiên cứu. Các thông tin cá nhân được đảm bảo giữ bí mật và chỉ phục vụ cho mục đích nghiên cứu

\section{KẾT QUẢ NGHIÊN CỨU}

Bảng 1. Thông tin chung của đối tượng nghiên cứu ( $n=250)$

\begin{tabular}{|c|c|c|c|}
\hline \multicolumn{2}{|c|}{ Biến số } & $\begin{array}{c}\text { Số } \\
\text { lượng }\end{array}$ & $\begin{array}{l}\text { Tỷ lề } \\
\text { (\%) }\end{array}$ \\
\hline \multirow{2}{*}{ Giới } & Nam & 116 & 464 \\
\hline & Nữ & 134 & 53,6 \\
\hline \multirow{4}{*}{ Nhóm tuổi } & $<70$ & 94 & 37,6 \\
\hline & $70-79$ & 119 & 47,6 \\
\hline & $>80$ & 37 & 14,8 \\
\hline & $\begin{array}{c}\text { TB } \pm \text { ĐLC } \\
(\min -\max )\end{array}$ & \multicolumn{2}{|c|}{$\begin{array}{c}72,5 \pm 7,2 \\
(49-96)\end{array}$} \\
\hline \multirow{2}{*}{$\begin{array}{l}\text { Thời gian } \\
\text { mắc tăng } \\
\text { huyết áp }\end{array}$} & $\leq 5$ năm & 84 & 33,6 \\
\hline & >5 năm & 166 & 66,4 \\
\hline \multirow{2}{*}{$\begin{array}{l}\text { Bệnh kèm } \\
\text { theo }\end{array}$} & Có & 86 & 34,4 \\
\hline & Không & 164 & 65,6 \\
\hline
\end{tabular}

Tỷ lệ nam và nữ trong nhóm bệnh nhân được quản lý điều trị tại TYT là tương đương nhau với tỷ lệ nam và nữ lần lượt là $46,4 \%$ và $53,6 \%$. Độ tuổi trung bình của nhóm BN là 72,5 tuối, người có độ tuổi nhỏ nhất được điều trị là 49 tuổi, và người có độ tuổi lớn nhất là 96 tuổi. Nhóm tuổi của BN được quản lý điều trị chủ yếu là 70-79 tuổi $(47,6 \%)$, tiếp đến là nhóm có độ tuổi $<70$ $(37,6 \%)$ và nhóm có độ tuổi $>80$ chiếm tỷ lệ thấp nhất $(14,8 \%)$. Những người được quản lý điêu trị có thời gian điều trị THA > 5 năm chiếm tỷ lệ $33,6 \%$, những người có thời gian điều trị THA < 5 năm chiếm tỷ lệ $66,4 \%$. 34,4\% BN có bệnh kèm theo, 65,6\% bệnh nhân không có bệnh kèm theo.

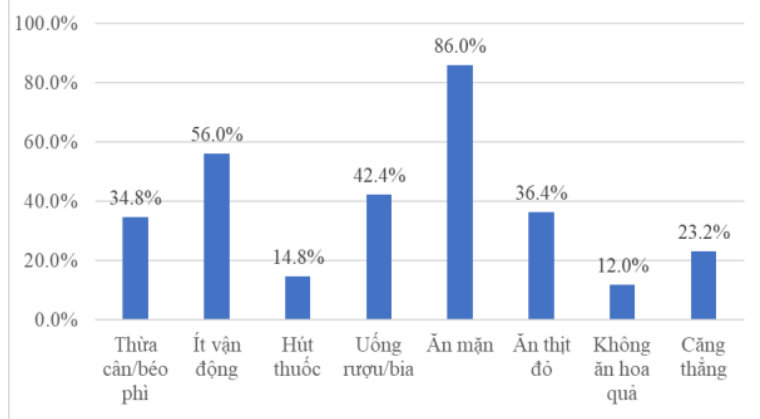

Biểu đồ 1. Một số thói quen không lành mạnh làm nặng hơn tinh trạng THA $(n=250)$

Thói quen không lành mạnh làm nặng thêm tình trạng THA chủ yếu là ăn mặn $(86 \%)$, ít vận động $(56 \%)$, uống rượu bia $(42,4 \%)$, ăn thịt đỏ $(36,4 \%)$ và thừa cân, béo phì $(34,8 \%)$.

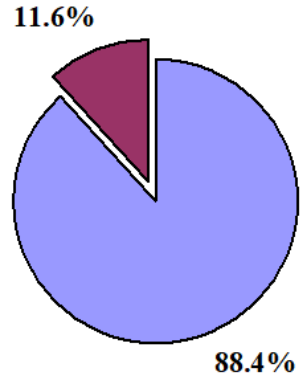

$\square$ Quản lý hiệu quả $\square$ Quản lý không hiệu quả

\section{Biểu đồ 2. Phân loại quản lý điều trị THA} $(n=250)$

Trong tổng số BN THA được quản lý điều trị, $88,4 \%$ BN được quản lý hiệu quả và $11,6 \%$ BN không được quản lý điêuu trị hiệu quả.

Bảng 2. Các yếu tố thuộc quá trinh quản lý điều trị THA $(n=250)$

\begin{tabular}{|c|c|c|}
\hline Yếu tố thuộc bản thân người bệnh & Số lượng (n) & Tỷ lệ (\%) \\
\hline Đạt huyết áp mục tiêu & 219 & 87,6 \\
\hline \multicolumn{3}{|l|}{ Yếu tố thuộc hệ thống y tế } \\
\hline Được điêu trị THA kịp thời ngay sau khi chẩn đoán THA & 237 & 94,8 \\
\hline Được NVYT chỉnh liều, đổi thuốc hay phối hợp thuốc & 240 & 96,0 \\
\hline $\begin{array}{c}\text { Được NVYT của trạm tư vấn chuyển lên tuyến trên điều trị khi } \\
\text { không kiểm soát được HA }\end{array}$ & 214 & 85,6 \\
\hline Được NVYT chủ động liên lạc mời tái khám & 232 & 92,8 \\
\hline
\end{tabular}




\begin{tabular}{|c|c|c|}
\hline Được NVYT tư vấn về tuân thủ điều trị, thay đối hành vi & 239 & 95,6 \\
\hline \multicolumn{3}{|l|}{ Yếu tố thuộc cá nhân người bệnh } \\
\hline Dùng thuốc thường xuyên & 245 & 98,0 \\
\hline Thường xuyên dùng thuốc đúng giờ & 238 & 95,2 \\
\hline Thường xuyên dùng thuốc đúng liêu & 238 & 95,2 \\
\hline Không tự động chỉnh liều thuốc & 244 & 97,6 \\
\hline Thay đổi lối sống sinh hoạt, hành vi giảm nguy cơ & 243 & 97,2 \\
\hline Thường xuyên đo kiểm tra huyết áp & 242 & 96,8 \\
\hline Thường xuyên ghi chép huyết áp và các thông tin liên quan vào số & 215 & 86,0 \\
\hline Thường xuyên theo dõi, tái khám theo hẹn & 198 & 79,2 \\
\hline Nhận được sự hỗ trợ từ người thân giúp nâng cao tuân thủ điều trị & 244 & 97,6 \\
\hline \multicolumn{3}{|l|}{ Nhân đước sư hố trơ từ xã hôi } \\
\hline Chia sẻ với hàng xóm/bạn bè về bệnh THA của mình & 189 & 75,6 \\
\hline $\begin{array}{c}\text { Được nhận sự khuyễn khích, động viên từ hàng xóm/bạn bè/người } \\
\text { quen trong điều trị THA }\end{array}$ & 227 & 90,8 \\
\hline
\end{tabular}

*THA: Tăng huyết áp, NVYT: Nhân viên Y tế

Các hành vi tuân thủ điều trị của bệnh nhân chiếm tỷ lệ cao (>95\%). Tỷ lệ bệnh nhân thay đổi lối sống sinh hoạt, ăn uống giảm nguy cơ chiếm $97,2 \%$. Trong quá trình quản lý điêu trị, $96,8 \%$ bệnh nhân thường xuyên đo kiểm tra huyết áp, 86\% bệnh nhân thường xuyên ghi chép huyết áo và các thông tin liên quan vào sổ và 79,2\% bệnh nhân theo dõi và tái khám theo hẹn.

Hầu hết BN nhận được sự hố trợ từ người thân giúp nâng cao tuân thủ điều trị $(97,6 \%)$. Tỷ lệ $B N$ chia sẻ với hàng xóm/bạn bè về bệnh THA của mình là $75,6 \%$ và có $90,8 \% \mathrm{BN}$ nhận được sự khuyến khích, động viên từ hàng xóm/bạn bè/người quen trong việc điều trị THA.

Bảng 3. Một số yếu tố liên quan đến quản lý điều trị THA qua phân tích đa biến

\begin{tabular}{|c|c|c|c|}
\hline \multicolumn{2}{|c|}{ Biến số } & $\begin{array}{c}\text { OR hiệu } \\
\text { chinh }\end{array}$ & $\mathbf{9 5 \%} \mathbf{C I}$ \\
\hline \multirow{3}{*}{ Nhóm tuổi } & $>80$ & 1 & \\
\cline { 2 - 4 } & $70-79$ & 8,00 & $2,02-31,57$ \\
\cline { 2 - 4 } & $<70$ & 6,80 & $1,79-25,69$ \\
\hline \multirow{2}{*}{$\begin{array}{c}\text { Bệnh kèm } \\
\text { theo }\end{array}$} & Có & 1 & \\
\cline { 2 - 4 } & Không & 3,21 & $1,20-8,59$ \\
\hline $\begin{array}{c}\text { Thời gian điều trị } \\
\text { tăng huyết áp }\end{array}$ & $\leq 5$ năm & 1 & \\
\cline { 2 - 4 } & $>5$ năm & 3,09 & $1,05-9,07$ \\
\hline Hút thuốc lá & Có & 1 & \\
\cline { 2 - 4 } & Không & 11,91 & $1,65-85,84$ \\
\hline Hoạt động thến & Không & 1 & \\
\cline { 2 - 4 } lực & Có & 6,89 & $1,94-24,42$ \\
\cline { 2 - 5 }
\end{tabular}

Mô hình hồi quy đa biến cho thẫy có mối liên quan giữa hiệu quả quản lý điều trị THA và nhóm tuổi, thời gian điều trị THA, bệnh kèm theo, hút thuốc lá và hoạt động thể lực. BN có độ tuổi từ $70-79$ và $<70$ tuổi có khả năng được quản lý điều trị THA cao hơn lần lượt là 8,00 lần (KTC $95 \%$ : $2,02-31,57$ ) và 6,80 lần (KTC $95 \%: 1,79$
- 25,69) so với nhóm BN có độ tuổi > 80. BN có thời gian điều trị THA > 5 năm có khả năng được quản lý điều trị THA hiệu quả cao hơn 3,09 lần (KTC 95\%: 1,05 - 9,07) so với những người có thời gian điêu trị THA $<5$ năm. BN không có bệnh kèm theo có khả năng được quản lý điều trị THA hiệu quả cao hơn 3,21 lần (KTC 95\%: 1,20 $8,59)$ so với những người có bệnh kèm theo. $\mathrm{BN}$ không hút thuốc lá có khả năng được quản lý điều trị THA hiệu quả cao hơn 11,91 lần (KTC $95 \%$ : 1,65 - 85,84) so với những người có hút thuốc lá. BN có hoạt động thể lực có khả năng được quản lý điều trị hiệu quả cao hơn 6,89 lần (KTC $95 \% / ; 1,94-24,42$ ) so với những người có hoạt động thể lực.

\section{BÀN LUẬN}

Khi hiệu quả quản lý điều trị bệnh nhân tại y tế cơ sở được đánh giá bởi các yểu tố thuộc hệ thống y tế, cá nhân người bệnh và sự hỗ trợ của người thân và xã hội, kết quả cho thẩy trong 250 bệnh nhân được quản lý điêu trị, $88,4 \%$ BN được quản lý hiệu quả và $11,6 \%$ BN không được quản lý điều trị hiệu quả. Ớ người lớn bị THA, việc kiểm soát đển mức độ không THA thông qua điêu trị không dùng thuốc và dùng thuốc làm giảm nguy cơ mắc các biến cố tim mạch và tử vong do mọi nguyên nhân từ $20-40 \%$. Khi bênh nhân đã được chẩn đoán và đưa vào hệ thống quản lý, cần thực hiện các biện pháp dùng thuốc và không dùng thuốc hiệu quả để hạ huyết áp. Cuối cùng, điều trị phải được tuân thủ và điều chỉnh để tối ưu hóa huyết áp và giảm nguy cơ xảy ra các biến cố tim mạch. Để đạt được các mục tiêu trên, mô hình chằm sóc bệnh mãn tính cũng nhấn mạnh vai trò của người bệnh là người 
chăm sóc chính cho tình trạng sức khỏe của ho. Bên cạnh đó cũng nhấn mạnh tầm quan trọng của các nhà cung cấp dịch vụ chăm sóc sức khỏe, sự hỗ trợ của gia đình và cộng đồng trong viêc tư quản lý [6]. Tình trang quản lý điêu tri hiệu quả chiếm tỳ lệ khá cao cho thấy sự phối hợp cao giữa bệnh nhân và hệ thống y tế, mối quan hê này rất quan trong trong viẹc hỗ trơ bênh nhân quản lý bênh THA của họ qua những lần khám, tư vấn và điều chỉnh trong kế hoạch điều trị, với mục tiêu đạt được sự chăm sóc tối ưu.

Tỷ lệ tuân thủ điều trị và thay đổi lối sống, giảm hành vi nguy cơ của bệnh nhân trong nghiên cứu của chúng tôi có tỷ lệ cao (>95\%), tương tự với nghiên cứu của Trần Đức Sĩ với tỷ lệ bênh nhân tư đánh giá tuân thủ điều tri tốt là $91,73 \%$ [4], và tương tự với kết quả nghiên cứu can thiệp của Lê Quang Thọ, sau can thiệp tỷ lệ người bệnh THA có thực hành cả 9 biện pháp điêu trị bênh THA chiếm 91,4\% [2]. Ngoài tuân thủ điều trị bằng thuốc ha áp, thực hành thay đổi hành vi lối sống, điều chỉnh chế độ dinh dưỡng, giảm muối, cai thuốc lá, hạn chế rượu bia, tăng cường hoạt động thể lực đóng góp quan trọng trong duy trì huyết áp mục tiêu, tỷ lệ này đạt $97,2 \%$ nhóm BN tham gia nghiên cứu.

Kết quả nghiên cứu của chúng tôi chỉ ra rằng BN có độ tuổi từ $70-79$ và <70 tuổi có khả năng được quản lý điều trị THA cao hơn lần lượt là 8,00 lần và 6,80 lần so với nhóm $B N$ có độ tuổi $>80$. Người cao tuổi có những vấn đề nghiêm trong như dùng quá nhiều thuốc một cách không hợp lý, tương tác thuốc và không tuân thủ phác đồ điêu trị. Vì thế việc quản lý điều trị cho những bệnh nhân cao tuổi sẽ găp nhiều khó khăn và có thể khó đạt được hiệu quả, và cần sư kiên trì phối hợp của cả nhân viên y tế, người thân và xã hội. Tương tự như vậy, những người có bệnh kèm theo sẽ có những vấn đề về dùng thuốc, tương tác thuốc và tuân thủ điều trị, tình trạng quản lý điều trị THA ở BN không có bệnh kèm theo trong nghiên cứu này có hiệu quả cao hơn 3,21 lần so với những người có bệnh kèm theo.

Thay đổi lối sống được khuyến cáo là phương pháp điều tr i đầu tiên cho tất cả bệnh nhân tăng huyết áp. Các nghiên cứu trước đây đã chỉ ra rằng kiểm soát cân nă̆ng, áp dung các phương pháp tiếp cận chế độ ắn uống để ngăn chặn tình trang tăng huyết áp, hạn chể natri trong chế độ ăn, tăng mức độ hoạt động và hạn chế uống rượu là những công cụ hiệu quả trong điều trị tăng huyết áp $[7,8]$. Trong nghiên cứu của chúng tôi cũng chỉ ra mối liên quan giữa không hút thuốc lá, có hoạt động thể dục và tình trạng quản lý điều trị hiệu quả.

\section{KẾT LUÂN}

Trong tổng số BN THA được quản lý điều trị, $88,4 \%$ BN được quản lý hiệu quả và $11,6 \%$ BN không được quản lý điều trị hiệu quả. Kết quả nghiên cứu cho thây có mối liên quan giữa hiệu quả quản lý điều trị THA và nhóm tuổi, thời gian điều trị THA, bệnh kèm theo, hút thuốc lá và hoạt động thể lực. BN có độ tuổi từ $70-79$ và $<70$ tuổi có khả năng được quản lý điêuu trị THA cao hơn lần lượt là 8,00 lần và 6,80 lần so với nhóm $\mathrm{BN}$ có độ tuổi $>80$. BN có thời gian điều trị THA $>5$ năm có khả năng được quản lý điều trị THA hiệu quả cao hơn 3,09 so với những người có thời gian điều trị THA < 5năm. BN không có bênh kèm theo có khả năng được quản lý điều trị THA hiệu quả cao hơn 3,21 lần so với những người có bệnh kèm theo. BN không hút thuốc lá có khả nắng được quản lý điều trị THA hiệu quả cao hơn 11,91 lần so với những người có hút thuốc lá. BN không hoạt động thể lực có khả năng được quản lý điều trị hiệu quả cao hơn 6,89 lần so với những người có hoạt động thể lực.

\section{TÀI LIÊU THAM KHẢO}

1. Bô $\mathbf{Y}$ tế, Điều tra quốc gia về các yếu tố nguy cơ của bểnh không lây nhiêm năm 2015, chủ biên, 2016.

2. Lề Quang Thọ, Đánh giá hiệu quả can thiệp trong quản lý tăng huyết áp tai huyên Ha Hòa, tỉnh Phú Thọ, Trường Đại hoc Y Hà Nội, 2019.

3. Sở Y tế tỉnh Quảng Ninh, Hạn chế bệnh không lây nhiếm - Cần kết hợp nhiều giải pháp, truy cập ngày Sep 17-2021, tại trang web http://www.soytequangninh.gov.vn/GD WS/Tintuc Chitiet.aspx?NewsId $=11112,2020$.

4. Trân Đức Sĩ, Nguyễn Hùng, Phan Kim Mỹ và cS, (2020), "Tuân thủ điều trị tăng huyết áp bằng thuốc của bênh nhân ngoại trú tại khao tim mach PKĐK Hoàn Mỹ Sài Gòn", Tạp chí Y học Việt Nam, 2020, 500(1), tr. 39-44.

5. WHO, Hypertension, truy cập ngày March 2-2021, tai trang web https://www.who.int/newsroom/fact-sheets/detail/hypertension.

6. R. M. Carey, P. Muntner, H. B. Bosworth, et al, "Prevention and Control of Hypertension: JACC Health Promotion Series", J Am Coll Cardiol, 2018, 72(11), tr. 1278-1293.

7. A. V. Chobanian, G. L. Bakris, H. R. Black, et al, "The Seventh Report of the Joint National Committee on Prevention, Detection, Evaluation, and Treatment of High Blood Pressure: the JNC 7 report", Jama, 2003, 289(19), tr. 2560-72.

8. G. A. Kelley, K. S. Kelley, "Progressive resistance exercise and resting blood pressure : A metaanalysis of randomized controlled trials", Hypertension, 2000, 35(3), tr. 838-43.

9. S. D. Pierdomenico, M. Di Nicola, A. L. Esposito, et al. "Prognostic value of different indices of blood pressure variability in hypertensive patients", Am J Hypertens, 2009, 22(8), tr. 842-7. 